\title{
Erros na fala da criança e instâncias subjetivas na sua relação com a língua
}

\author{
Irani Rodrigues Maldonade \\ Universidade Estadual de Campinas (UNICAMP), Campinas, São Paulo, Brasil \\ irani@fcm.unicamp.br
}

DOI: $\underline{\text { http://dx.doi.org/10.21165/el.v45i2.785 }}$

\begin{abstract}
Resumo
Este artigo objetiva refletir sobre alguns erros na aquisição do léxico e da morfologia verbal na fala de uma criança brasileira, durante o processo de aquisição da linguagem. Para interpretá-los, o quadro teórico interacionista é convocado. São enfocados os diálogos em que a criança reformula o seu dizer a partir do efeito de estranhamento (ou surpresa) que o erro em sua fala produz na fala do outro. São analisadas as situações: a) em que ao reformular o seu dizer, a escuta da língua não é sinalizada na fala da criança e b) em que ao reformular o seu dizer, a escuta da língua é sinalizada na fala de M. Argumenta-se que esses fenômenos permitem ilustrar instâncias subjetivas que identificam a posição da criança na sua relação com a língua.
\end{abstract}

Palavras-chave: aquisição da linguagem; erros; fala da criança.

\section{Errors in a child's speech and subjective instances in his relation to language}

\begin{abstract}
This article aims at reflecting on some errors in the lexical and verbal morphology acquisition in the speech of a Brazilian child, during the language acquisition process. To interpret these errors, the interactionist theoretical framework was used. This study focuses on dialogues in which the child reformulates his speech because of the effect of strangeness (or surprise) that his speaking errors produce in other people's speech. Two different situations were analyzed: a) when the child reformulates what he is saying, the hearing of the language is not revealed in his speech and $b$ ) when the child reformulates what he is saying, the hearing of the language is revealed in his speech. It is argued that these phenomena allow illustrating subjective instances that identify this child's position in his relationship to language.
\end{abstract}

Keywords: language acquisition; errors; child's speech.

\section{Introdução}

Nos estudos de aquisição da linguagem, muito tem se falado sobre os erros na fala singular da criança, mas poucos são os trabalhos que se voltam para analisar a condição de escuta que a criança tem da língua. Neste artigo, não deixamos de lado os efeitos da fala da criança na fala do adulto, mas nos dedicamos a observar, principalmente, a fala da criança na sua relação com a língua em funcionamento. Vale assinalar, logo de início, aqui, o sentido que damos ao termo "fala da criança". Basicamente, este indica que a fala da criança, de acordo com sua natureza é diferente em relação à fala adulta. Porém, essa diferença não chega a atrapalhar no diálogo e na relação da criança com o adulto, pois "apesar da heterogeneidade e imprevisibilidade da fala da criança, do ponto de vista linguístico, falantes dirigem-se a ela e a interpretam como um falante de sua língua", 
como afirma De Lemos (2006, p. 23). Além disso, sabe-se que a interpretação que o adulto faz da fala da criança é crucial para que a criança se constitua como sujeito falante.

É nesse sentido que se pode afirmar que a criança depende do outro para se escutar, pois o que ela diz encontra, no diálogo, uma significação que vai possibilitar, posteriormente, a fala. Por conta disso é que se explica também a impossibilidade de analisar a fala da criança isoladamente. É no diálogo que sua fala vai ganhando sentido, tornando-se, assim, interpretável. Segundo Beltrão e Carvalho (2008), o diálogo dá lugar ao outro. Para as autoras, esse outro não tem a função de fornecer a língua ou de adicionar um conhecimento linguístico à criança; não a ensina a falar, mas simplesmente fala com/por ela.

Segundo Castro (2006), a teorização interacionista propõe uma visão estrutural da mudança como sendo o fenômeno primeiro da aquisição da linguagem. Isso acontece, de acordo com a autora, por conta de que o reconhecimento da ordem própria da língua, que é sustentada tanto por Saussure quanto por Chomsky, não pode ser sustentado a partir de uma visão desenvolvimentalista em aquisição da linguagem, conforme o que é proposto por De Lemos (2002). Sendo assim, esta autora rompe com a perspectiva desenvolvimentalista dominante na área e sustenta, coerentemente com a noção de autonomia da língua, a função desta como "captura".

Dessa forma, a partir do conceito de captura é que De Lemos (2002) define o fenômeno da mudança que ocorre no processo de aquisição da linguagem, como "mudança de posição em uma estrutura". Ou seja, no percurso da criança de infans a sujeito falante ocorrem mudanças de posição da criança relativamente à fala do outro, à língua e, consequentemente, à sua própria fala. E, desse percurso, os erros na fala da criança - dados privilegiados para análise entre os pesquisadores da perspectiva interacionista -, também fazem parte. Eles estão presentes durante todo processo de aquisição da linguagem, embora apareçam de forma mais concentrada na segunda posição da criança no processo de aquisição da linguagem.

Cabe registrar que o tema deste artigo - "Erros na fala da criança e instâncias subjetivas na sua relação com a língua" - decorre dos resultados obtidos em etapas anteriores das pesquisas que desenvolvi durante o estágio de pós-doutorado. Inicialme nte, foi dado relevo ao efeito produzido (na fala do outro) pelo erro na fala de $\mathbf{M}^{1}$, na medida em que se investigava o deslocamento do sujeito da segunda para a terceira posição no processo de aquisição da linguage $\mathrm{m}^{2}$, proposto por De Lemos (2002). Naquela ocasião, foi também possível recortar dois movimentos da língua na fala da criança, que foram posteriormente retomados em outro trabalho ${ }^{3}$ à luz do quadro teórico proposto por Jakobson (1974): a) aquele em que parte da mensagem remetia à própria mensagem e b)

\footnotetext{
1 Trata-se da abreviação do nome da criança brasileira que gravei des de um ano e meio até quatro anos e meio de idade, cujos dados subsidiaram vários trabalhos, tais como a dissertação de mestrado (MALDONADE, 1995), a tese de doutorado (MALDONADE, 2003) e alguns artigos (MALDONADE, 2010, 2011, 2012 e 2014). Os diálogos em que a fala da criança apresentava erros (com verbos, principalmente) foram registrados em um diário, constituindo, assim, outra fonte de armazenamento de dados de M. A metodologia utilizada foi a longitudinal observacional, ou seja, a mesma desenvolvida por outros investigadores da perspectiva teórica interacionista iniciada por De Lemos (1982).

2 Desenvolvi o projeto "Os erros na fala da criança: sobre o deslocamento do sujeito da segunda para a terceira posição no processo de aquisição da linguagem” para o estágio de pós-doutorado em 2010.

${ }^{3}$ Desenvolvi o projeto "Instâncias da língua na fala da criança" em outra etapa do estágio de pós -doutorado em 2013.
} 
aquele em que parte da mensagem remetia ao código. O conjunto de dados analisado, na ocasião, permitiu verificar que a criança não tomava a língua como objeto da mesma forma que o adulto o faria: como objeto de conhecimento ou diversão. Antes, os dados deixaram indicado o início da condição de escuta da língua pela criança e sua não coincidência com o saber da língua. Dessa forma, o objetivo aqui será o de refletir sobre os diálogos em que, ao reformular o seu dizer, a escuta da língua é sinalizada ou não na fala de M. Acredita-se que esses fenômenos permitem ilustrar as instâncias subjetivas, que ajudam a identificar a posição da criança na sua relação com a língua.

Para desenvolver o tema aqui proposto, apresento, na próxima seção, em linhas gerais, o quadro teórico interacionista e, em seguida, a análise de alguns dados da fala de $\mathrm{M}$, no tocante à abertura para a condição de escuta da língua pela criança.

\section{Referencial teórico}

O quadro teórico que referencia este e outros trabalhos anteriores é o interacionismo, desenvolvido por De Lemos (desde 1982) e colaboradoras, entre eles, Figueira (1996, 2008) e Castro (1998, 2006). Essa perspectiva teórica sempre se recusou a descrever a fala da criança através de categorias dadas pela descrição linguística. Ao contrário, propôs o diálogo entre criança e adulto como unidade de análise, conferindo à interação um estatuto teórico. Dessa forma, os enunciados da criança deixam de ser tomados como índices de conhecimento categorial da língua, o que chegou a ser considerado, pelos pesquisadores interacionistas, como uma atitude ingênua frente aos desafios que a fala da criança impunha. Foi preciso, então, lançar mão de outros recursos teórico-metodológicos, para descrever e explicar como as propriedades estruturais da linguagem podiam ser derivadas de processos de interação linguístico-discursivos. Para isso, a proposta dos processos metafóricos e metonímicos (DE LEMOS, 1992) foi fundamental.

Entretanto, um passo a mais foi necessário para livrar a fala da criança de uma visão desenvolvimentalista: atrelar os processos metafóricos e metonímicos à especificidade de seus efeitos e à articulação da posição do sujeito na língua, uma vez que era preciso tanto romper com a ideia de uma cronologia específica para o processo de aquisição da linguagem, quanto à de ordenação na aquisição de estruturas linguísticas (na direção das mais simples para as mais complexas). Delineou-se, então, a proposta das três posições da criança no processo de aquisição da linguagem (DE LEMOS, 2002), indicando que as mudanças que ocorrem na fala da criança são mudanças relativas à fala do outro, à língua e à sua própria fala. Tal proposta apresenta-se, até hoje, como uma alternativa à noção de desenvolvimento. De Lemos (2002) impõe às três posições uma visão estrutural, de modo a poder afirmar que elas não são nem ordenáveis entre si, nem determinadas cronologicamente. Diferentemente, elas se assentam sobre a alteridade radical da língua relativamente ao organismo, porque o sujeito ao se constituir na e pela língua(gem) é, ao mesmo tempo, atravessado por ela. A partir disso, Maldonade (2015) afirma que aquilo que acontece na fala de uma criança pode não se repetir na fala de outra, pois há a singularidade do sujeito (sua subjetividade), que diz respeito à sua estruturação como sujeito falante. Isso significa que seu trajeto é único no processo de aquisição da linguagem, o que o torna um sujeito falante diferente de outro.

De acordo com a proposta da autora, verifica-se, na primeira posição, a fala da criança submetida à fala do outro, de forma que se mostra o efeito de semelhança entre 
as cadeias linguísticas da fala do outro e da fala da criança. Já na segunda posição, notase a fala da criança presa ao movimento da língua, ocasião em que o erro tende a aparecer. Observa-se também, nessa posição, algum grau de distanciamento da fala da criança com relação à fala do outro, promovido pelo deslocamento da criança da primeira para a segunda posição. Esse deslocamento é percebido do ponto de vista linguístico, pelo fato de que é a fala da própria criança que se oferece para a sustentação dos movimentos dos significantes que nela são ressignificados e, não mais, a fala do outro, como acontece em larga escala na primeira posição. Entretanto, será necessário ainda mais outro deslocamento da criança, desta vez da segunda para a terceira posição, em que se observa a dominância da relação do sujeito com sua própria fala. Nessa última posição, as reformulações, as hesitações, as correções e autocorreções podem acontecer. A pergunta que se faz aqui é: nesses deslocamentos da criança, o que se pode dizer sobre as posições subjetivas?

De fato, a teorização interacionista conclui que a mudança (linguística e subjetiva) é o aspecto essencial do processo de aquisição da linguagem. Esta é sinalizada pelo deslocamento da criança nessas posições durante o processo de aquisição da linguage $m$. Normalmente, os estudos da área concentram-se apenas nas mudanças linguísticas, consideradas como construções cumulativas sobre a língua, aprendidas pelas crianças durante o processo de aquisição da linguagem, que é concebido como processo de aprendizagem. Entretanto, todos os esforços na teorização interacionista têm sido realizados para não deixar de lado nem o sujeito nem a língua na explicação para o processo de aquisição da linguagem. Desta forma, o que se tem chamado de desenvolvimento da linguagem como processo de subjetivação põe em questão não só o processo de aquisição de linguagem como aquisição de um conhecimento sobre a língua, quanto o pressuposto de que esse conhecimento adquirido implique em desenvolvimento. De acordo com De Lemos (2001), falar em processo de subjetivação significa colocar a anterioridade lógica da linguagem relativamente a um corpo pulsional que é por ela capturado e significado. Isso equivale a dizer que mudanças linguísticas implicam, ao mesmo tempo, em mudanças subjetivas; sendo que o erro na fala da criança faz parte disso. Pode até mesmo, sem exageros, ser considerado o protagonista.

No interacionismo, ele é concebido como produto do movimento da língua na fala da criança em determinado momento de seu trajeto, no processo de aquisição da linguagem. O erro não atinge sempre as mesmas estruturas linguísticas e também não aparece na mesma proporção na fala de dois sujeitos durante o processo de aquisição da linguagem. É considerado, portanto, como marca (ou ponto) de subjetivação. Por essas razões, a imprevisibilidade e o caráter contingente do erro na fala da criança são sempre assinalados por pesquisadores interacionistas (FIGUEIRA, 1996, 2008; MALDONADE, 1995, 2003).

Contudo, a proposta das três posições da criança no processo de aquisição da linguagem apresenta algumas dificuldades, quando confrontada com dados, uma vez que a definição de cada uma das posições leva em consideração os pontos extremos dos polos relacionais: a fala do outro, a língua e a fala da própria criança. Na segunda posição proposta por De Lemos (2002), o que está em jogo é o retorno do linguístico sobre si mesmo e a impermeabilidade da criança à correção. Porém, em trabalho anterior (MALDONADE, 2011) foi possível surpreender a situação em que a criança (M) modificava sua própria fala em resposta ao estranhamento da fala do outro. Isso mostrou que a criança não estava alheia ao pedido do adulto. Ao contrário, parecia haver 
reconhecimento de alguma diferença entre sua fala e a do outro, porém as (novas) relações estabelecidas não fizeram desaparecer o erro de sua fala. Por isso, na ocasião, optou-se por assinalar o princípio da condição de escuta da língua pela criança e não a impermeabilidade à correção. Além disso, foi possível mostrar o papel fundamental e decisivo da fala do outro nesse processo; posição esta contrária à de Karmiloff-Smith (1986, 1995), ao afirmar que o processo reorganizacional (ou de análise linguística) ocorre à margem da experiência da criança com a linguagem.

Para explorar um pouco mais de perto essas questões, propõe-se, na próxima seção, analisar os diálogos em que a $\mathrm{M}$ reformula o seu dizer a partir do efeito de estranhamento (ou surpresa) que o erro em sua fala produz na fala do outro, focalizando as instâncias subjetivas que se delineiam no processo de constituir-se como sujeito falante.

\section{Apresentação e discussão dos dados}

Antes de apresentar os dados, torna-se necessário fornecer algumas informações sobre a metodologia usada nesta pesquisa qualitativa. A metodologia utilizada é longitudinal observacional, ou seja, a mesma desenvolvida por outros investigadores da perspectiva teórica interacionista iniciada por De Lemos (1982). Isso significa que os dados da fala de $\mathrm{M}$ foram colhidos em situações de diálogos espontâneos, no dia a dia da criança com seus familiares. Sendo assim, os dados da fala de M são do tipo naturalístico, colhidos em sessões de gravações semanais desde 1;6 (um ano e seis meses) até 4;6 (quatro anos e seis meses) de idade, com duração de 45 minutos. Tanto a investigadora quanto os familiares participavam das sessões de gravação. M é a terceira filha (a caçula) de um casal de classe média paulista brasileira, em que o pai tinha nível de ensino superior incompleto e a mãe nível de ensino médio incompleto. $M$ apresentava boa saúde e não havia quaisquer queixas com relação ao seu desenvolvimento geral. A diferença de idade de $\mathrm{M}$ com suas irmãs era de 7 e 9 anos.

Depois das gravações, foram realizadas as transcrições (largas) dessas sessões, suas revisões e, posteriormente, trechos foram selecionados para análise de dados, de acordo com o objetivo da pesquisa. Além desses dados colhidos em sessões de gravação, outros dados foram anotados em um caderno diário pelos familiares, constituindo, assim, a segunda fonte de dados para a pesquisa. A investigadora solicitava aos familiares que anotassem os diálogos em que erros apareciam na fala de $\mathrm{M}$.

Apresento, a seguir, algumas ocorrências relacionadas a erros no domínio da morfologia verbal na fala de $\mathrm{M}$, em que ao reformular o seu dizer, a escuta da língua não é sinalizada na fala da criança.

$2 ; 10.12^{4}$

I: Você tomô banho de manhã? Por quê?

\footnotetext{
4 Os números separados por ponto e vírgula, e depois por ponto, representam a idade da criança na ocorrência em questão. Assim, 2;10.12 significa: dois anos, dez meses e doze dias. Se depois dos números ainda aparecer a letra $\mathrm{D}$, entre parênteses, indica que o dado foi registrado no diário (a outra fonte de dados existente). Caso contrário, ele é de gravação. As outras abreviaturas referem-se à: investigadora (I), mãe de M (S), pai de M (L), irmã mais velha de M (Dani), outra irmã, também mais velha do que M (Mari), prima de $\mathrm{M}$ (AC), primo de $\mathrm{M}$ (Chico) e outra prima de M (A).
} 
M: Poque tomi.

I: $\tilde{A}$ ?

M: Tava fedida de chulé.

(um pouco adiante no mesmo diálogo)

I: Mas, por que que cê tomô banho Marcelinha?

M: Mas eu tomi ta/(repira) fedida.

I: Mas que cê fez pra ficá fedida logo cedo? Que que cê fez?

M: Fez cocô na calça, xixi.

I:Você? (espanto) Você fez cocô na calça?

M: Não, (respira) xixi. Cocô na/ na privada! (brava!)

Na primeira ocorrência, observa-se que depois do estranhamento de I da fala de M, que apresenta o erro (tomi), este volta a aparecer na fala da criança, quando pergunta semelhante the é endereçada. Note-se, que o mas da segunda pergunta de I reaparece na resposta subsequente da criança em mas eu tomi ta/(repira) fedida, mostrando o jogo paralelístico entre as cadeias que retornam da fala do adulto para a da criança, deixando à mostra o processo de identificação entre elas. Entretanto, esse espelhamento não é total, pois apesar de o adulto ter manifestado seu estranhamento do erro na primeira resposta de $\mathrm{M}$, ele reaparece pela segunda vez na fala da criança. É possível assinalar aqui a posição subjetiva de M, que se apresenta como "surda" ao pedido de correção feito pelo adulto.

Algo na mesma direção argumentativa pode ser observado na próxima ocorrência.

2;11.15

I: Marcela, sabia que a Ana Cláudia ficô doente do ouvido?

M: Chabio.

I: Sabia?

M: Eu sabio. Coraçãozão! (I acabou de desenhar um coração na mão de M)

Sabio, em 2, manifesta-se na fala de $\mathrm{M}$ no lugar que, do ponto de vista da gramática da língua, era esperado sabia. Acontece que as formas verbais de primeira, segunda e terceira pessoas são coincidentes neste tempo verbal. Não há a marcação do/o/ desinencial para as formas de primeira pessoa, no imperfeito, no entanto, ela aparece na fala de $\mathrm{M}$, produzindo o erro de flexão verbal. Registram-se, ao lado disso, nesse momento, erros semelhantes, tais como: ero, tavo e tinho, que guardam entre si uma semelhança estrutural: o /o/ final, uma maneira de deixar registrada a pessoa na forma verbal. Coisa semelhante se observa com ouvo, cabo e medo. Tais erros emergem no ponto de conversão do discurso do outro em discurso próprio. Os erros de flexão verbal concedem-nos o privilégio de flagrar alguns momentos deste movimento na fala de $\mathrm{M}$. Em 2, apesar de sabia manifestar-se na fala de I, imediatamente anterior à de $\mathrm{M}$, na fala da criança surge sabio, forma que guarda uma relação de semelhança com sabia e, diferença, na medida em que uma substituição é feita através do /o/, marcação desinencial típica da primeira pessoa, para o presente do indicativo, mas não para a primeira pessoa do imperfeito. Produz-se, assim, o erro na fala da criança. Ele indica que a criança já não está tão dependente da fala do outro, como na primeira posição da criança no processo 
de aquisição da linguagem, onde só se verifica a semelhança entre cadeias da fala do outro na fala da criança. A posição subjetiva de $\mathrm{M}$ assinala que há um ponto de diferenciação, que vem à tona pela flexão verbal. Na ocorrência 2, mesmo após o estranhamento do adulto, a forma que (re)aparece na fala de M é sabio, em Eu sabio. Por isso De Lemos (2002) afirmou que a impermeabilidade à correção é a principal característica da segunda posição da criança no processo de aquisição da linguagem.

Note o que se passa na próxima ocorrência.

$$
\begin{aligned}
& \text { 2;06.00 (D) (na sala com Dani) } \\
& \text { M: Dani, fazí sujera no chão. } \\
& \text { Dani: O que? } \\
& \text { M: Caiu banana. Pega! }
\end{aligned}
$$

Às vezes, o pedido de correção do erro na fala da criança pode ser mais sutil, como o o que? da fala de Dani, no diálogo em questão. Porém o que se verifica em 3 é que o diálogo prossegue e o erro não volta a acontecer na fala da criança.

É preciso acrescentar que nem sempre o erro é estranhado na fala da criança, como em 4

(4) 2:06.18 (D)

S: Hum, que cheirinho bom!

M: O pai fazeu café.

L: (da cozinha) Já tá saindo.

Note-se que não há espelhamento entre a fala do outro e a de $\mathrm{M}$, como também se viu em 3. Do lado da língua, o erro mostra uma forma não esperada pela gramática da língua adulta, ou ainda, outra possibilidade combinatória da língua. E do lado do sujeito, o erro mostra justamente o trabalho singular do sujeito com a língua, na língua, em que se verifica uma mudança de posição da criança com relação à fala do outro, da qual já não é mais tão dependente.

Confira, na sequência, outras ocorrências, em que ao reformular o seu dizer, a escuta da língua é sinalizada na fala de M. Comecemos pelos erros na aquisição lexical.

(5) $\quad 2 ; 02.20$

I: Por que que cê tá toda riscada de caneta na perna, hein? Que que é is so?

M: Vanecha quevô a minha peina.

I: Quem?

M: Fô Melecha?

I: Vô Menessa? (estranhando)

M: Vanecha. Não. Ane/

Dani: Vanessa.

M: Menessa. É Manessa queveno mia ?iado.

S: Escreveu minha perna? (repetindo) A Vanessa, uma pinóia. 
I: Quem que foi? M: Uai, ai, ai ${ }^{5}$. (tinha sido M que havia se rabiscado)

No episódio 5, M aponta Vanecha corno sendo culpada pelos rabiscos que ela mesma fizera em sua perna. Chama-nos a atenção o fato de que frente à pergunta de I (Quem?), M modifica seu dizer para Melecha, palavra que o adulto também estranha ou parece não entender. I repete Vô Menessa, mostrando não ter entendido o que a criança quis dizer. Diante disso, M diz Vanecha e sua irmã, Dani, ajusta a palavra do ponto de vista fonológico, ao dizer Vanessa. Porém, na fala de M, aparecem: Menessa (forma da fala anterior de I) e Manessa. O que se nota é que diante do que parece ser um simples pedido de repetição de sua fala, $M$ modifica seu dizer de modo a tornar a palavra ainda mais estranha aos ouvidos de seus interlocutores. Depois do segundo estranhamento do adulto, a palavra é dita exatamente como da primeira vez, neste episódio, na fala de M. Tendo em vista as modificações que a criança faz em sua fala, é possível concluir aqui que ela é sensível tanto ao pedido de correção feito pelo adulto, como também mostra sua condição de escuta para a língua, mesmo não tendo conseguido pronunciar a palavra como o esperado, Vanessa.

Não é possível ignorar também que a sequência Vanecha quevô, em que o verbo escrever, de segunda conjugação, conforme gramática do português é reposto na fala de M como se fosse de primeira conjugação, o que pode ser identificado pelo sufixo verbal. Esses aspectos mostram o trabalho substancial da criança com a língua, na língua, no seu processo de aquisição da linguagem.

Observe, em 6, outra ocorrência relacionada à aquisição lexical.

(6) 2; 01.28 (a conversa gira em tomo de um passeio que $\mathrm{M}$ fez ao bosque)

S: Mas qual bicho que tinha? A mãe cochicha pro cê assim. (S cochicha no ouvido de $\mathrm{M}$ )

M: Macaco.

I: Tinha macaco?

M: Tinha.

I: Que mais?

M: Patcho. (baixo)

S: Fala alto, senão ela não escuta.

M: Patcho. (alto)

I: Patcho? (estranha)

M: Pato!

I: Que mais?

M: Pato tá codando.

$\mathrm{I}: \tilde{\mathrm{A}}$ ?

M: Pato (a)codeu. O pato/

S: O pato escondeu aonde?

M: Aqui.

\footnotetext{
${ }^{5}$ Quando dois enunciados são escritos na mesma linha, significa que eles foram ditos concomitantemente. Ou seja, são enunciados que foram ditos por dois interlocutores diferentes e que aconteceram ao mesmo tempo.
} 
S: Conta pra lrani que tinha hipopótamo.

M: Hipopoto.

Na ocorrência 6, ao conversar sobre um passeio que fez, Patcho (dito pela primeira vez com pouca intensidade) aparece na fala de M. Após a solicitação da mãe (S) para aumentar sua voz, M repete a mesma palavra (patcho) com mais intensidade, colocando-a em relevo e provocando o estranhamento de I. Em seguida, pato (que é a forma esperada) aparece na fala de M. Mostra-se aqui que a fala de $M$ não está alheia à solicitação de correção de I. Além disso, sua posição subjetiva deixa assinalado que a criança tem escuta para a língua, dada a correção que faz em sua própria fala.

O efeito de estranhamento da fala de M não para por aí. Codeu chama a atenção para algo que vai além da simples alteração de classe de conjugação, em que se vislumbra substituição de um sufixo da primeira conjugação, /ou/, pelo da segunda conjugação, /eu/, do ponto de vista da gramática convencional. Na fala de $\mathrm{M}$, antes da sequência que contém o erro, há outra que merece atenção: pato tá codando, que parece não ter sido entendida por I, que diz: Ã? Em seguida, no diálogo, M diz: pato (a)codeu, em que o $a$ foi dito com tom de voz muito baixo. Não há como ignorar o paralelismo entre as sequências pato tá codando e pato (a)codeu. Note-se que há uma substituição de tá codando por (a)codeu (processo metafórico) na estrutura, que é ressignificada (recolocada) na fala da criança. Com isso, é possível apontar que a cadeia linguística que serviu de base para a substituição encontra-se na fala da própria criança e, não mais, na fala do outro, imediatamente anterior à de $\mathrm{M}$, como na primeira posição.

A movimentação dos significantes nas sequências paralelísticas na fala de $\mathbf{M}$ permite destacar a posição da criança, neste caso, submetida ao movimento da língua, movimento este que atravessa sua fala. Digno de atenção é o destino de codeu no diálogo. Ele foi interpretado pela mãe, $\mathrm{S}$, que interrompeu a fala de $\mathrm{M}$ logo em seguida, como se fosse a forma reduzida de outro verbo, o esconder. Ela pergunta em seguida: o pato escondeu aonde? M responde: Aqui, provavelmente atendendo a requisição do aonde que comparece na fala da mãe. O fato é que codeu guarda tanto uma relação de semelhança com escondeu, como foi a interpretação indicada pela fala da mãe, quanto uma semelhança com acorda, relação estabelecida na fala de $\mathrm{M}$.

Siga, abaixo, como a fala de M se apresenta diante de uma correção feita pela fala de sua mãe.

(7) 2;05.00 M: Pé! (choraminga)

S: Que que tem teu pé?

M: Meu pé, machuqui.

S: Machuqui/. (estranha)

M:É.

S: Não, "machuquei!" (corrige)

M: Machucô.

S: Machucô o pé. Machucô? Onde? Aonde? Não tô vendo nada.

M: Qué Maliana.

S: Mariana saiu.

M: Hum, ca êta. 
S: Ca êta.

M: É

A ocorrência 7 é exemplar para mostrar a resposta de $\mathrm{M}$, frente à solicitação de correção do erro feita por sua mãe $(S)$ de Machuqui, que comparece na fala de $M$, que do ponto de vista da língua mostra uma alteração da classe de conjugação verbal, da primeira para a segunda ou terceira. A mãe de $\mathrm{M}$, que percebe o erro dito pela criança, solicita a correção. Primeiramente, a mãe repete: machuqui, com uma entonação que demonstrou seu estranhamento, à qual $\mathrm{M}$ apenas acrescenta: $E$. Logo em seguida, S, ela mesma faz a correção, uma vez que seu estranhamento não conseguiu produzir efeito sobre a fala da criança: Não, machuquei, diz ela. M diz: Machucô. No entanto, interessante é que machuquei da fala da mãe, disponível para a deriva não é ressignificada na fala de M. Manifesta-se machucô, forma de segunda pessoa, trazendo de volta, mesmo sem saber disso, o verbo para sua classe paradigmática. Com relação à instância subjetiva de M no diálogo, é possível dizer que $\mathrm{M}$ não fica alheia ao pedido de correção feito pela mãe, visto que dá uma resposta efetiva a ele. Porém, é possível observar, através da resposta que dá, o quanto se afasta da adequação esperada pela mãe. Na sequência do diálogo, a mãe parece desistir da correção da fala da criança, voltando a falar machucô.

Observe a ocorrência que vem a seguir.

(8) $\quad 3 ; 00.22$

S: Que que tinha no Crea (clube)?

M: Tinha (respira) um coelhinho.

S: Que mais? Que que cê fez com o coelhinho?

M: Di um papá.

S: Di. (estranha)

I: $\tilde{A}$ ?

M: Deu papá.

S: Que mais? Que cê fez com/ que que cê fez com o coelhinho? Que que tava dando pra ele?

M: Papá.

S: Que papá que tava dando?

M: Folhinha.

I: Folha, Marcela?! Por que cê não deu arroze feijão?

M: Puque que é/ ele/ ele não gosta.

I: Ah, Marcela! Lógico que ele gosta. Será que não?

M: Nem eu fui lá.

I: Que que cê deu pra ele?

M: Pu que cê não foi lá?

I: Ah, porque ontem eu fui no sítio do Maurício.

M: Ah, tão gostoso! Vai lá!

I: É?

M: É. 
Em 8, di surge na fala de $\mathrm{M}$, no lugar em que seria esperada a forma verbal flexionada em primeira pessoa. Vale a pena observar o fato de não haver qualquer forma do verbo em questão na fala do outro, anterior à da criança. A fala de $\mathrm{M}$ provoca um estranhamento em $\mathrm{S}$, que a repete: $D i$ e, na sequência, I também manifesta o seu, ao dizer: $\tilde{A}$ ?. No entanto, logo em seguida, comparece na fala da criança a forma de segunda pessoa, deu. M parece ter sido afetada pelo estranhamento que sua fala provocou nos interlocutores, contudo, em sua fala, na sequência, aparece a forma verbal correspondente de segunda pessoa. Na primeira posição, registrou-se a presença de verbos de segunda (ou terceira pessoas), que eram fragmentos da fala do outro na fala de $\mathrm{M}$, decorrentes da alienação de sua fala à do outro. Na ocorrência em questão, isso não se verifica. O que parece ter mudado é sua posição subjetiva: embora não se mostre alheia ao pedido de correção do adulto, não consegue fazer aparecer a forma esperada em sua fala.

Ao finalizar a discussão dos dados, apresento uma última ocorrência que ilustra bem o que vem sendo mostrado com relação à posição subjetiva de $\mathrm{M}$.

(9) 3;00.07 (Dani coloca algo em M)

I: Não cabe mais, M!

M: Assim.

I: Não cabe. Dani:

Não cabe. Você era muito pequenininha.

M: Eu não era!

Dani: Era!

M: Não ero.

Dani: Tô falando/ "Não ero!" Ai, que coisa feia!

I: Era sim! Cê

M: Não ero! (alto)

I: Era! Você era! (alto, tentando corrigir M)

M: Is so é palavrão?

Dani: Não é palavrão, só que tá errado.

M: Hã, SI (baixo)

I: A Marcela era tão pequenininha!

M: E(pausa)ra, e não cabia isso.

Dani: Cabia?

A impermeabilidade de $\mathrm{M}$ à correção, característica da segunda posição proposta por De Lemos (2002), pode ser assinalada em alguns episódios, na fala de M. Na ocorrência 9, em que $\mathrm{M}$ diz ero, soa até engraçado, pois a criança chega a perguntar ao interlocutor se se tratava de palavrão, dada sua posição de não escuta da língua. 


\section{À guisa de conclusão}

Ao partir das considerações feitas na seção anterior, é possível afirmar que nem sempre o erro causa estranhamento entre os interlocutores da criança. Nas ocorrências 3 e 4, o diálogo simplesmente segue seu curso. É preciso enfatizar que ele não é resultado de processo de aprendizagem, alinhável numa rota de desenvolvimento que possa ser prescrita.

As ocorrências 1 e 2 foram exemplares no sentido de mostrar que mesmo sob o efeito do estranhamento de sua fala pelo interlocutor, o erro comparece na fala de $\mathrm{M}$. Desta forma, foi possível assinalar a posição subjetiva de $\mathrm{M}$, que se apresenta como que "surda" ao pedido de correção feito pelo adulto e/ou à escuta da língua. Ou seja, concordamos com De Lemos (2002) ao afirmar que a impermeabilidade à correção é a principal característica da segunda posição da criança no processo de aquisição da linguagem. Já a ocorrência 5 mostra que $\mathrm{M}$ é sensível ao pedido de correção feito pelo adulto, assim como mostra a escuta que tem da língua, mesmo que não tenha conseguido pronunciar a palavra Vanessa, como o esperado de acordo com a língua adulta já constituída. Em 6, observou-se que a criança se abre para a escuta da língua, dada a correção que faz em sua própria fala. Em 7 e 8, a fala da criança não se mostra impermeável à correção feita pelo adulto, mas a forma correta da palavra não aparece na fala de M. Porém, em 9, a fala da criança não só se mostra impermeável à correção feita pelo adulto, como indica que a fala da criança não se abre para escuta da língua.

Sendo assim, dadas essas flutuações, parece-me mais adequado nos referirmos às instâncias subjetivas na fala de $\mathrm{M}$, nesse momento de seu processo de aquisição da linguagem, do que simplesmente às posições subjetivas. Aliás, o termo posição subjetiva confere à subjetividade um aspecto de algo já constituído; o que me parece contrário à ideia de que o sujeito está em constituição no processo de aquisição da linguagem.

Na teorização interacionista, tanto o estranhamento quanto o reconhecimento são decorrentes da mudança da relação da criança com sua língua, ou seja, são os pilares responsáveis pelas instaurações de instâncias subjetivas, como os dados da fala de M puderam mostrar. Desta forma, é possível entender, conforme De Lemos (1992) indica a partir da leitura que fez de Lacan, que os processos metafóricos e metonímicos (que regem a movimentação das cadeias linguísticas na fala da criança) não remetem, exclusivamente, a um movimento autônomo da língua sobre si mesma, mas a um sujeito, ou melhor, a um modo de emergência de um sujeito na cadeia significante. De acordo com a autora,

Pensar o sujeito como efeito da linguagem equivale, pois, literalmente, a subverter uma concepção de sujeito enquanto posicionada face a linguagem como objeto de conhecimento a ser apreendido ou construído. Ou, em outras palavras, a considerar a criança, enquanto corpo pulsional, como capturada pelo funcionamento da língua na qual é significada, por um outro, como falante, antes mesmo de o ser. Nesse sentido, pode-se dizer que essa captura tem o efeito de colocá-la em uma estrutura em que comparece o outro como instância de interpretação e o Outro como depósito e rede de significantes. Essa estrutura é a mesma em que se move o adulto (que é também o outro da criança), enquanto sujeito falante também submetido ao Outro. (DELEMOS, 2002, p. 5-6, grifo meu) 
Sendo assim, um aspecto de subjetivação dessa posição estrutural é reconhecível na identificação da criança com a fala do outro, incorporada por ela. Em outras palavras, os efeitos de semelhança e diferença entre a fala da criança e a do outro mostram as faces de uma subjetivação emergente. Seguindo esse mesmo raciocínio, Castro (1998, p. 256) afirma que

[...] a aquisição da língua materna põe o sujeito na posição de falante, isto é, passa a qualificá-lo a partir desse momento lógico de captura por um modo de funcionamento, sempre dividido entre la langue e língua, o que me permitiu, em trabalhos anteriores, afirmar que a língua materna deva ser compreendida como uma experiência única, impossível de ser esquecida mesmo quando a julgamos perdida; mesmo se não a reconhecemos mais na superfície da fala, mesmo se falamos uma língua estrangeira.

Não poderia deixar de finalizar este artigo sem antes fazer algumas considerações sobre o estranhamento do adulto do erro na fala da criança e sua consequente correção. Para Lima (2010), o adulto está sob os efeitos da fala da criança e essa fala pode lançá-lo na posição daquele que tem um saber que a criança ainda não tem e, estando nessa posição, ele a corrige. Para a autora, a correção é uma das imposições que a fala do adulto exerce sobre a fala da criança. É também uma forma de aproximar a fala da criança à do adulto.

\section{REFERÊNCIAS}

BELTRÃO, F. R. C.; CARVALHO, G. A singularidade do papel do outro na aquisição de linguagem de crianças abrigadas. Psicologia: teoria e prática, São Paulo, v.10, n.1, p. 79-94, 2008.

CASTRO, M. F. P. Sobre a interpretação e os efeitos da fala da criança. Letras de Hoje, Porto Alegre, v.33, n.2, p. 81- 87, 1998.

. Sobre o (im)possível esquecimento da língua materna. In: LIER-DE-VITTO, M. F.; ARANTES, L. (orgs.). Aquisição, Patologias e Clínica de linguagem. São Paulo: Editora PUC-SP EDUC, 2006. p. 135-148.

DE LEMOS, C. G. Sobre a aquisição da linguagem e seu dilema (pecado) original. Boletim da Abralin, n.3, p. 97-126, 1982.

Los processos metafóricos y metonímicos como mecanismo de cambio.

Substratum, n.1, p. 121-135, 1992.

Desenvolvimento da linguagem e processo de subjetivação. Comciência, São Paulo, 10 ago. 2001. Disponível em: $<\mathrm{http} / / \mathrm{www}$. comciencia.br/reportagens/linguagem/ling17.htm\#notas >. Acesso em: 20 abr. 2016.

Das vicissitudes da fala da criança e de sua investigação. Cadernos de Estudos Linguísticos, Campinas, n.42, p. 41-69, 2002.

Uma crítica (radical) à noção de desenvolvimento na Aquisição da Linguagem. In: In: LIER-DE-VITTO, M. F.; ARANTES, L. (orgs.). Aquisição, Patologias e Clínica de linguagem. São Paulo: Editora PUC-SP EDUC, 2006. p. 21-32. 
FIGUEIRA, R. O erro como dado de eleição nos estudos de aquisição da linguagem. In: CASTRO, M. F. C. (org.). O método e o dado no estudo da linguagem. Campinas: Editora da UNICAMP, 1996. p. 55-86.

Quando reflexividade e aquisição da linguagem se encontram: jogos, réplicas e reformulações. In: CONGRESSO INTERNACIONAL DA ALFAL, XV, 2008, Montevidéu. Anais... Montevidéu: ALFAL, 2008, CD do evento.

JAKOBSON, R. Linguística e Comunicação. 2. ed. São Paulo: Cultrix, 1969 [1963]. 162 p.

Ensayos de Linguística General. Tradução de J. Pujol e J. Cabanes. Barcelona: Editorial Seix Barral, 1974. 406 p.

KARMILOFF-SMITH, A. From meta-processes to conscious access: evidence from children metalinguistics and repair data. Cognition, v.23, p. 95-147, 1986.

LIMA. G. A. A fala da criança e seus efeitos no adulto interlocutor. Cadernos do CNLF, Rio de Janeiro, v. XI, n.2, t.2, p. 1924-1934, 2010.

MALDONADE, I. R. Erros na aquisição de verbos com alternância vocálica: uma análise sócio-interacionista. 1995. 211 f. Dissertação (Mestrado em Linguística) Instituto de Estudos da Linguagem, Universidade Estadual de Campinas, Campinas.

Erros na aquisição da flexão verbal: uma análise interacionista. 2003. 167 f. Tese (Doutorado em Linguística) - Instituto de Estudos da Linguagem, Universidade Estadual de Campinas, Campinas.

Erros na aquisição da flexão verbal: reflexividade e constituição do paradigma verbal. Estudos Linguísticos, São Paulo, v.39, n.2, p. 462-476, 2010.

Algumas considerações sobre o erro e a autocorreção no processo de aquisição da linguagem. Estudos Linguísticos, São Paulo, v.40, n.2, p. 539-552, 2011.

O erro e a autocorreção na relação da criança com a língua. Estudos Linguísticos, São Paulo, v.41, n.2, p. 403-418, 2012.

Universal e singular: instâncias da língua na fala da criança. In: DA HORA, D. et al. (orgs.). ALFAL 50 anos: contribuições para os estudos linguísticos e filológicos. João Pessoa: Ideia, 2015. p. 1622-1649.

Recebido em: 05/10/2015

Aprovado em: 10/08/2016 